\title{
Exploring physicians' comfort level with opioids for chronic noncancer pain
}

\author{
Martin N Scanlon PhD MD¹, Urmil Chugh MA MEDes ${ }^{2}$
}

\begin{abstract}
MN Scanlon, U Chugh. Exploring physicians' comfort level with opioids for chronic noncancer pain. Pain Res Manage 2004;9(4):195-201.
\end{abstract}

OBJECTIVE: To explore the attitudes of family physicians (FPs) toward the use of opioids in the management of chronic noncancer pain (CNCP) in the Calgary Health Region (CHR), Calgary, Alberta. METHODS: From January to February 2003, random samples of 147 FPs (32 were used to pretest the instrument and were therefore excluded from the findings) and 142 specialists practicing in the CHR were invited to participate in a 20 min survey to explore aspects of CNCP management in the CHR. Physicians' comfort in prescribing opioids and nonsteroidal anti-inflammatory drugs for CNCP was measured on a fourpoint ordinal scale. The specialists' subgroup served as a quasi-control group. In addition, a short version of the survey was provided for those physicians who declined to fully partake in the study. This allowed the researchers to compare important characteristics between respondents and nonrespondents.

RESULTS: A total of 125 physicians (63 FPs and 62 specialists) participated in the study. The overall response rate was $48.6 \%$ and response rates for FPs and specialists were $54.8 \%$ and $43.7 \%$, respectively. Response rates for the long version of the survey were $42.6 \%$ for FPs $(n=49), 31.6 \%$ for other specialists $(n=45)$ and $36.6 \%$ for both combined.

The majority of FPs and specialists (98\% and $71.1 \%$, respectively) reported that 'they can handle' nonsteroidal anti-inflammatory drugs, Tylenol No 3 with Codeine (Janssen-Ortho/McNeil Consumer Healthcare, Canada) (95.9\% and 64.4\%, respectively), morphine/MS Contin (Purdue Pharma, Canada) (61.2\% and $24.4 \%$, respectively) and Percocet (Bristol-Myers Squibb, Canada)/OxyContin (Purdue Pharma, Canada) (61.2\% and 33.3\%, respectively). Fewer FPs and specialists report that 'they can handle' Dilaudid (Abbott Laboratories, Canada)/Hydromorph Contin (Purdue Pharma, Canada) $(36.7 \%$ and $13.3 \%$, respectively), fentanyl patch $(30.6 \%$ and $11.1 \%$, respectively) and methadone ( $0 \%$ and $6.7 \%$, respectively).

Male FPs reported a greater degree of comfort than female FPs regarding morphine/MS Contin, Percocet/OxyContin and Dilaudid/ Hydromorph Contin (Mann-Whitney $U$ tested at $\alpha \leq 0.05$ ). No sex differences were detected among specialists. No relationship was detected between comfort and years of practice or number of chronic pain patients in practice. Among specialists, a weak positive relationship was detected between the degree of comfort with methadone (Spearman's rank correlation coefficient $=0.35, \alpha=0.03$ ) and the significance of pain management in the practice. Except for methodone, the FPs reported a higher confidence with the drugs in question compared with specialists $(\alpha \leq 0.05)$.

CONCLUSIONS: FPs in the CHR need to increase their comfort level toward opioids in general to adequately manage CNCP. Their lack of comfort may reflect a lack of education or fear of regulatory scrutiny.

Key Words: Chronic pain management; Continuing medical education; Opioids; Pain education; Treatment

\section{Explorer le sentiment d'aisance des médecins à l'égard des opiacés dans le traitement des douleurs non cancéreuses chroniques}

OBJECTIF : Explorer les attitudes des médecins de famille (MF) envers l'usage des opiacés dans la prise en charge de douleurs non cancéreuses chroniques (DNCC) dans la région sanitaire de Calgary (RSC), à Calgary, en Alberta.

MÉTHODOLOGIE : De janvier à février 2003, un échantillonnage aléatoire de $147 \mathrm{MF}$ (dont 32 ont failt l'essai préliminaire du sondage et ont donc été exclus des résultats) et de 142 spécialistes exerçant dans la RSC ont été invités à participer à un sondage de 20 minutes afin d'explorer les aspects de la prise en charge des DNCC dans la RSC. L'aisance des médecins à prescrire des opiacés et des anti-inflammatoires non stéroïdiens (AINS) pour les DNCC a été mesurée sur une échelle ordinale à quatre points. Le sous-groupe de spécialistes représentait un quasi-groupe témoin. De plus, une courte version du sondage a été remise aux médecins qui ont refusé de participer à l'ensemble de l'étude. Les chercheurs ont ainsi pu comparer des caractéristiques importantes entre les répondants et les nonrépondants.

RÉSULTATS : Au total, 125 médecins (63 MF et 62 spécialistes) ont participé à l'étude. Le taux de réponse global était de 48,6\%, et les taux de réponse des MF et des spécialistes s'élevaient à $54,8 \%$ et à $43,7 \%$, respectivement. Les taux de réponse à la version longue du sondage correspondaient à $42,6 \%$ pour les MF $(n=49)$, à $31,6 \%$ pour les spécialistes $(n=45)$ et à $36,6 \%$ pour les deux groupes combinés.

La majorité des MF et des spécialistes (98\% et 71,1\%, respectivement) ont déclaré "pouvoir gérer » les AINS Tylenol no 3 avec codéine (JanssenOrtho/Soins-santé grand public McNeil, Canada) (95,9\% et $64,4 \%$, respectivement) la morphine et MS Contin (Purdue Pharma, Canada) (61,2 \% et 24,4\%, respectivement) et Percocet (Bristol-Myers Squibb, Canada) et OxyContin (Purdue Pharma, Canada) $(61,2 \%$ et $33,3 \%$, respectivement). Moins de MF et de spécialistes déclaraient « pouvoir gérer » le Dialudid (Laboratoires Abbott, Canada) et l'Hydromorph Contin (Purdue Pharma, Canada) (36,7 \% et 13,3\%, respectivement), le timbre de fentanyl $(30,6 \%$ et $11,1 \%$, respectivement) et la méthadone $(0 \%$ et $6,7 \%$, respectivement)

Les MF de sexe masculin démontraient un plus grand sentiment d'aisance que ceux de sexe féminin à l'égard de la morphine et du MS Contin, du Percocet et de l'OxyContin et du Dialudid et de l'Hydromorph Contin (test U de Mann-Whitney à $\alpha \leq 0,05$ ). Aucune différence entre les sexes n'a été perçue chez les spécialistes. Aucun lien n'a été décelé entre l'aisance et les années de pratique ou le nombre de patients souffrant de douleurs chroniques de la clientèle. Parmi les spécialistes, un faible lien positif a été observé entre le sentiment d'aisance à l'égard de la méthadone (coefficient de corrélation de rang de Spearman=0,35, à $\alpha=0,03$ ) et l'importance de la prise en charge de la douleur dans la pratique. À part la méthadone, les MF faisaient état d'un plus grand degré de confiance que les spécialistes à l'égard des médicaments indiqués $(\alpha \leq 0,05)$.

CONCLUSIONS : Les MF de la RSC doivent accroître leur sentiment d'aisance à l'égard des opiacés en général pour bien prendre en charge les DNCC. Leur peu d'aisance peut refléter une absence de formation ou une crainte des vérifications par les organismes de réglementation.

\footnotetext{
${ }^{1}$ Department of Anesthesiology, University of Calgary, ${ }^{2}$ Evaluation and Research Consultant, Calgary, Alberta

Correspondence and reprints: Dr Martin N Scanlon, Calgary Pain Centre, Calgary Health Region, 160-2210 2nd Street Southwest, Calgary,

Alberta T2S 3C3. Telephone 403-943-9900, fax 403-209-2954, e-mail martinscanlon@calgaryhealthregion.ca
} 
Thentions he use of opioids in managing chronic noncancer pain (CNCP) in adults has been a controversial issue in medical literature. In 2003, Gardner-Nix (1) cautioned that omitting opioids in $\mathrm{CNCP}$ management without clinical and scientific justification, stops patients from receiving much needed relief. Gardner-Nix stated that "Opioids can be beneficial and safe as a component of the long-term management of non-cancer pain" (1). Eighty (38\%, $\mathrm{n}=209$ ) of Gardner-Nix's (1) CNCP patients (followed for two to 15 years) experienced reduced pain with concomitantly increased physical function compared with preopioid treatment.

A 2002 original article (2) concluded that in Canada, chronic pain is undertreated because physicians underutilize major opioids in spite of growing empirical evidence supporting their use in the management of CNCP. The literature is replete with articles describing evidence and recommendations in favour of using opioids and the most effective ways to use them (3-8). A recent survey (8) conducted with Canadian physicians (palliative care and family physicians [FPs]) revealed that approximately $28 \%$ were unwilling to prescribe short- or long-acting opioids for the management of chronic pain, even as a third-line treatment. According to some experts, the role of opioids in the management of chronic pain is not well-established (9). Russell and Aaron (10) acknowledged the benefits of judicious use of opioids under extraordinary circumstances but, by and large, expressed skepticism toward them. The majority of responding physicians in a 1994 American study (11) reported that they were not overly concerned by potentials of tolerance, dependence or addiction when prescribing opioids. The College of Physicians and Surgeons of Alberta have published guidelines to help manage local cases (12).

There is a need for primary care physicians to increase their comfort level with opioids to adequately treat patients suffering from moderate to severe chronic pain. A recent study (8) reported that approximately $60 \%$ of participating physicians felt that "pain management could be enhanced by improved physician education" (8). Further, the need for education among clinicians was recognized by an international panel. It concluded that, while progress has been made, much remains to be done to correct unfounded fears and misconceptions that impede the provision of opioid analgesia when it is indicated (4). Turk et al (11) considered physicians' education in pain management to be inadequate, both during medical school and in residency programs. Weinstein et al (13) concluded that new strategies are needed to educate physicians to manage CNCP. Goldman's 1991 article (14) painted a negative picture of physicians dealing with CNCP patients (eg, inept).

The present article is part of a larger study conducted in 2002/2003 to explore multiple aspects of chronic pain management in Calgary, Alberta. One such aspect was physicians' comfort in managing opioids including Tylenol No 3 with Codeine (Janssen-Ortho/McNeil Consumer Healthcare, Canada), morphine/MS Contin (Purdue Pharma, Canada), Percocet (BristolMyers Squibb, Canada)/OxyContin (Purdue Pharma, Canada), Dilaudid (Abbott Laboratories, Canada)/Hydromorph Contin (Purdue Pharma, Canada), fentanyl patch and methadone. The study was funded by the Physician Partnership Steering Committee at the Calgary Health Region (CHR), and the unpublished report is titled 'Physicians' and patients' perspectives on chronic pain management in the Calgary Health Region (CHR): Exploring the next step toward chronic pain management in the CHR". The present article contributes to the debate on physicians' readiness to manage chronic pain with special emphasis on opioid therapy. The purpose is to share and explore findings from a larger study about physicians' comfort level in managing opioids including Tylenol No 3 with Codeine, morphine/MS Contin, Percocet/OxyContin, Dilaudid/Hydromorph Contin, fentanyl patch and methadone. Although data are collected from various specialties, the main focus is on the CHR's FPs because they are the gatekeepers of the CNCP among Calgarians.

\section{METHODS}

One hundred forty-seven FPs and 142 specialists were randomly selected from the College of Physicians and Surgeons of Alberta's 2002 Medical Directory (15) using the MINITAB Statistical Software (Minitab Inc, USA). Approximately 893 FPs (in the directory, this group of physicians are also referred to as nonspecialists) and 661 specialists were considered to be eligible for this study (ie, two sampling frames were constructed, one for the FPs and one for the specialists). Some may consider family practice to be a specialty in its own right. Of the 50 types of specialists listed in the medical directory, 22 types were arbitrarily selected for the present study. The two sample sizes from the two subpopulations were expected to be representative at a $95 \%$ CI with a sampling error of \pm 0.05 . This was contigent on a $60 \%$ to $70 \%$ response rate. Theoretically, the response rate should be $100 \%$, but the CI was not the sole factor in deciding on an efficient sample size. Other factors such as variability of the important variables, need for subpopulation analysis and cost were also considered (16).

A 20 min survey was designed to explore several questions related to CNCP in the CHR (eg, to what extent can FPs and specialists deal with chronic pain without the intervention of pain specialists? and how well prepared do these physicians feel in managing chronic pain patients?). The present paper focuses on a subquestion of the above, namely, how comfortable do CHR physicians feel in prescribing opioids and what factors influence their comfort level? The complete survey was composed of 23 closed- or open-ended questions and additional subquestions.

Thirty-two FPs (12 responded, 37.5\% response rate) were invited to pretest the survey for clarity. Participants had the flexibility to complete the survey by telephone, fax, e-mail or regular mail.

One hundred fifteen FPs (excluding the above 32 invited for pretesting) and 142 specialists were telephoned to conduct the pretested survey. Physicians who declined to participate in the full survey were asked to supply information on their type of practice, number of hours devoted to direct patient care, number of patients in practice and significance of chronic pain in their practice. These parameters were compared between the respondents and nonrespondents to examine selection bias.

In the full survey, physicians were asked to indicate their level of comfort in managing six opioids: Tylenol No 3 with Codeine, morphine/MS Contin, Percocet/OxyContin, Dilaudid/Hydromorph Contin, fentanyl patch and methadone in noncancer chronic pain management. For the sake of comparison, the comfort level for nonsteroidal anti-inflammatory drugs (NSAIDs) was also solicited. The comfort level was measured on a four-point ordinal scale as a proxy measure for drug use by physicians. Responses were coded numerically from four to one.

- Handle myself (code 4): I handle all aspects myself;

- Somewhat uncertain (code 3): I would read/check the CPS (Compendium of Pharmaceuticals and Specialties) first;

- Specialist's advice (code 2): I would like advice and direction from a specialist, and would then manage the patient myself; and

- Specialist manage (code 1): I would not use this myself, but would like a specialist to manage it. 
TABLE 1

Sixteen participating physicians' specialties $(n=45)$

\begin{tabular}{lc}
\hline Specialty & $\mathbf{n}(\%)$ \\
\hline Cardiology & $1(2.2)$ \\
Emergency medicine & $2(4.4)$ \\
Gastroenterology & $1(2.2)$ \\
General surgery & $3(6.7)$ \\
Internal medicine & $3(6.7)$ \\
Neurology & $2(4.4)$ \\
Neurosurgery & $1(2.2)$ \\
Obstetrics and gynecology & $3(6.7)$ \\
Ophthalmology & $1(2.2)$ \\
Orthopedic surgery & $8(17.8)$ \\
Pediatrics & $2(4.4)$ \\
Physical medicine and rehabilitation & $1(2.2)$ \\
Plastic surgery & $2(4.4)$ \\
Psychiatry & $13(28.9)$ \\
Sports medicine & $1(2.2)$ \\
Transplant surgery & $1(2.2)$
\end{tabular}

TABLE 2

Descriptive statistics relating to length of service

\begin{tabular}{lcc}
\hline & \multicolumn{2}{c}{ Value (years) } \\
\cline { 2 - 3 } Statistic & Family physicians $(\mathbf{n}=\mathbf{4 6})$ & Specialists $(\mathbf{n}=\mathbf{4 1})$ \\
\hline Mean & 20.7 & 22.5 \\
SD & 11.6 & 8.6 \\
Median & 20 & 22 \\
Mode & 11 & 13 \\
Minimum & 4 & 7 \\
Maximum & 46 & 46 \\
\hline
\end{tabular}

The coded data were entered for statistical analysis by the Statistical Package for the Social Sciences 11.01 for Windows (SPSS Inc, USA).

Using comfort level as an ordinal dependent variable, the MannWhitney $\mathrm{U}$ test was performed to determine differences in comfort level between male and females (independent variable). In addition, Spearman's rank correlation coefficients (rho) were computed between comfort level and length of practice, number of chronic pain patients in the practice, and self-reported five-point level of significance of chronic pain in physicians' practice (extremely significant, very significant, moderately significant, mildly significant and not at all significant). Eight variables emerging from the larger survey were mentioned here: comfort with the seven drugs, type of physician, significance of chronic pain in physicians' practices, number of pain patients in practice, weekly hours devoted to direct patient care, sex, length of practice and the province of graduation. Data concerning physicians' sex, length of practice (length between graduation year and the time of the survey) and province of graduation were all obtained through the medical directory (15).

\section{RESULTS}

Forty-nine FPs and 45 specialists (Table 1) consented to partake in the 20-min survey (long survey). The response rates were $42.6 \%$ and $31.6 \%$, respectively.

Thirty-six of 49 (73.5\%) FPs and 31 of 45 (68.9\%) specialists graduated in Canada (Alberta, Ontario, Saskatchewan, Quebec, British Columbia and Manitoba). The majority of both the FPs

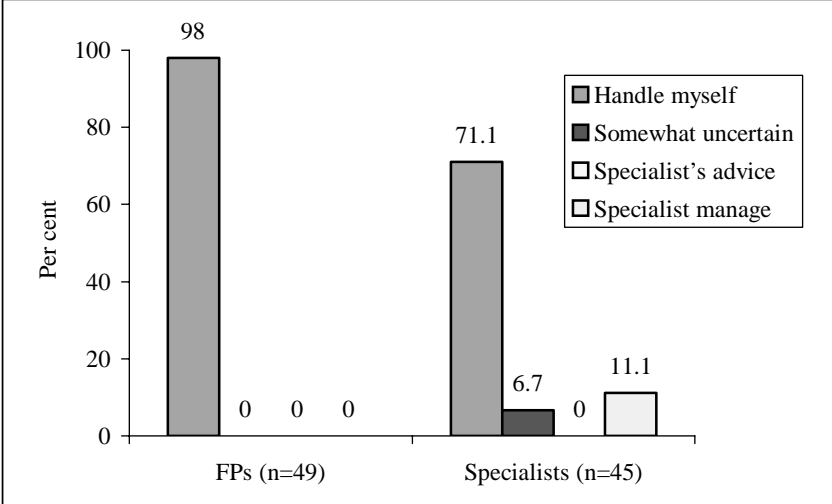

Figure 1) Comfort with nonsteroidal anti-inflammatory drugs. FP Family physician

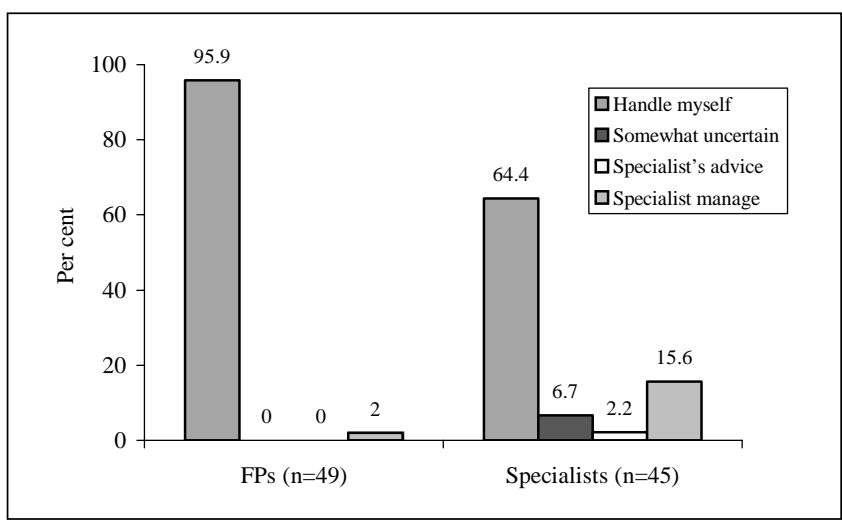

Figure 2) Comfort with Tylenol No 3 with Codeine (JanssenOrtho/McNeil Consumer Healthcare, Canada). FP Family physician

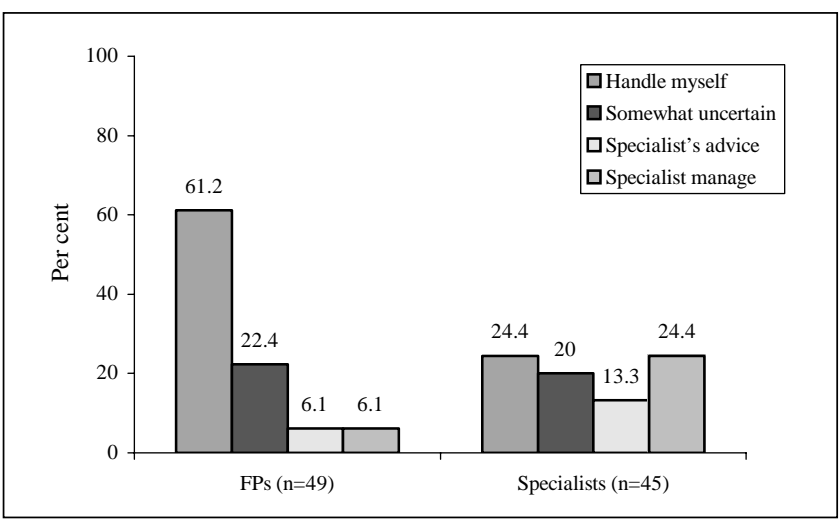

Figure 3) Comfort with morphine/MS Contin (Purdue Pharma, Canada). FP Family physician

(53.0\%) and specialists (48.8\%) graduated in Alberta (University of Calgary or University of Alberta, Edmonton). FPs $(n=42)$ reported managing anywhere from six to 1200 chronic pain patients $($ mean $=84.2, \mathrm{SD}=189$, median $=30$, mode $=10)$. Specialists $(n=24)$ reported managing anywhere from one to 400 chronic pain patients ( mean=62.6, $\mathrm{SD}=118.9$, median=10, mode=5). The forms of chronic pain included backache, headache, fibromyalgia, pelvic pain, and neuropathic pain with backache prominent within both the subgroups. Table 2 presents descriptive statistics for the length of service of both the FPs and specialists.

Figures 1 to 7 compare FPs' and specialists' comfort profiles (frequency distribution of responses) for seven drugs individually. 


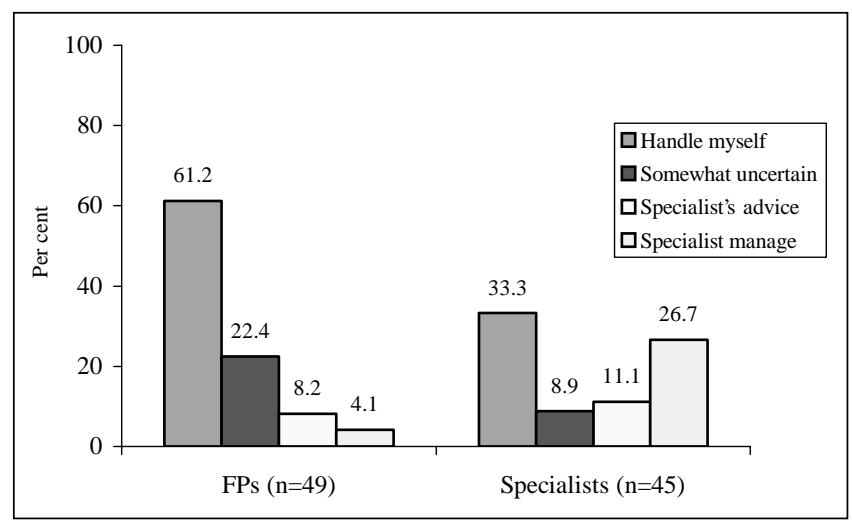

Figure 4) Comfort with Percocet (Bristol-Myers Squibb, Canada)/ OxyContin (Purdue Pharma, Canada). FP Family physician

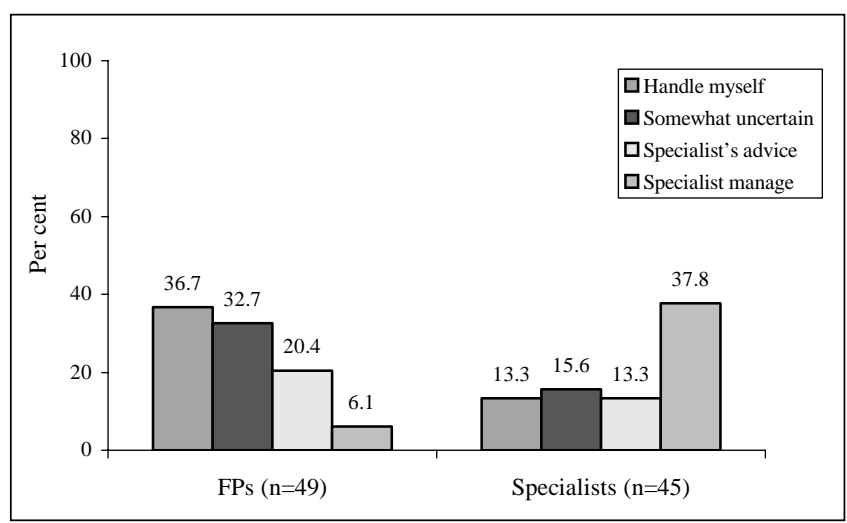

Figure 5) Comfort with Dilaudid (Abbott Laboratories, Canada)/ Hydromorph Contin (Purdue Pharma, Canada). FP Family physician

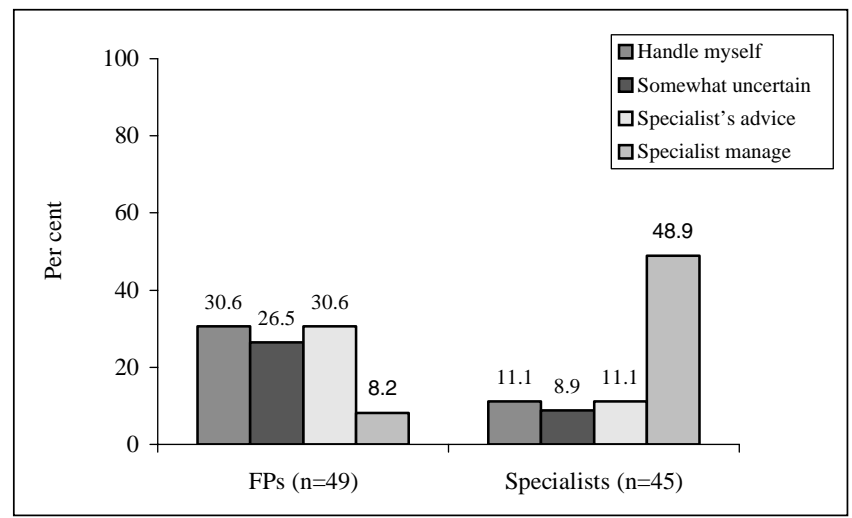

Figure 6) Comfort with fentanyl patch. FP Family physician

The Mann-Whitney $U$ test revealed that, compared with the specialists, FPs express a higher level of comfort with six of the seven drugs in question. Methadone appeared to be the exception because the specialist subgroup had a higher mean ranking (Table 3).

The Mann-Whitney $U$ test revealed no significant $(\alpha>0.05)$ difference in comfort level between male and female FPs when prescribing NSAIDs, Tylenol No 3 with Codeine, fentanyl patch and methadone. However, when managing

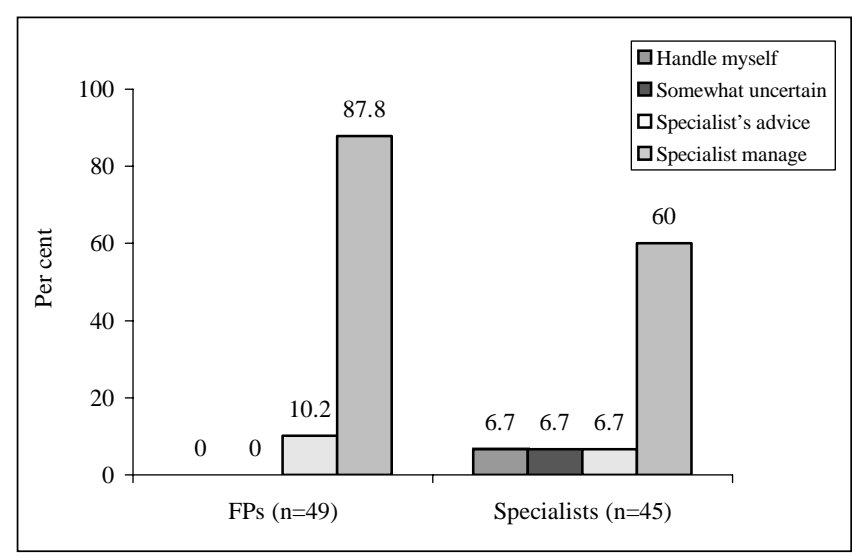

Figure 7) Comfort with methadone. FP Family physician

\section{TABLE 3}

Significant Mann-Whitney tests detecting differences in comfort with opioids between family physicians (FPs) and specialists

\begin{tabular}{|c|c|c|c|}
\hline Drug & Mean rank & Mann-Whitney U & $\alpha$ value \\
\hline \multicolumn{4}{|c|}{ Nonsteroidal anti-inflammatory drugs } \\
\hline FPs $(n=48)$ & 48.50 & 768 & 0.001 \\
\hline Specialists $(n=40)$ & 39.70 & & \\
\hline \multicolumn{4}{|c|}{ Tylenol No 3 with Codeine* } \\
\hline FPs $(n=48)$ & 49.54 & 718 & 0.001 \\
\hline Specialists $(n=40)$ & 38.45 & & \\
\hline \multicolumn{4}{|l|}{ Morphine/MS Contin ${ }^{\dagger}$} \\
\hline FPs $(n=47)$ & 50.38 & 499 & 0 \\
\hline Specialists $(n=37)$ & 32.49 & & \\
\hline \multicolumn{4}{|l|}{ Percocet $^{\ddagger} / O x y$ Contin ${ }^{\dagger}$} \\
\hline FPs $(n=47)$ & 48.13 & 558 & 0.004 \\
\hline Specialists $(n=36)$ & 34.00 & & \\
\hline \multicolumn{4}{|c|}{ Dialudid§/Hydromorph Contin ${ }^{\dagger}$} \\
\hline FPs $(n=47)$ & 50.46 & 448 & 0 \\
\hline Specialists $(n=36)$ & 30.96 & & \\
\hline \multicolumn{4}{|l|}{ Fentanyl patch } \\
\hline FPs $(n=47)$ & 51.47 & 401 & 0 \\
\hline Specialists $(n=36)$ & 29.64 & & \\
\hline \multicolumn{4}{|l|}{ Methadone } \\
\hline FPs $(n=48)$ & 39.57 & 723 & 0.049 \\
\hline Specialists $(n=36)$ & 46.42 & & \\
\hline
\end{tabular}

*Janssen-Ortho/McNeil Consumer Healthcare, Canada; tPurdue Pharma, Canada; ${ }^{\prime}$ Bristol-Myers Squibb, Canada; §Abbott Laboratories, Canada

morphine/MS Contin, Percocet/OxyContin and Dialudid/ Hydromorph Contin, male FPs reported a greater level of comfort compared with their female counterparts. Table 4 presents the frequency distribution broken down by sex within the two subgroups. Table 5 presents statistically significant $(\alpha<0.05)$ Mann-Whitney U results. No significant sex differences were found among specialists when managing any of the seven drugs. Only eight female specialists participated in the study.

Based on a Spearman correlation test (at $\alpha \leq 0.05$ ), there were no relationships (neither positive nor negative) between the comfort levels with the seven drugs being tested and the two independent variables in either of the two subgroups 
TABLE 4

Physicians' sex difference in comfort with opioids

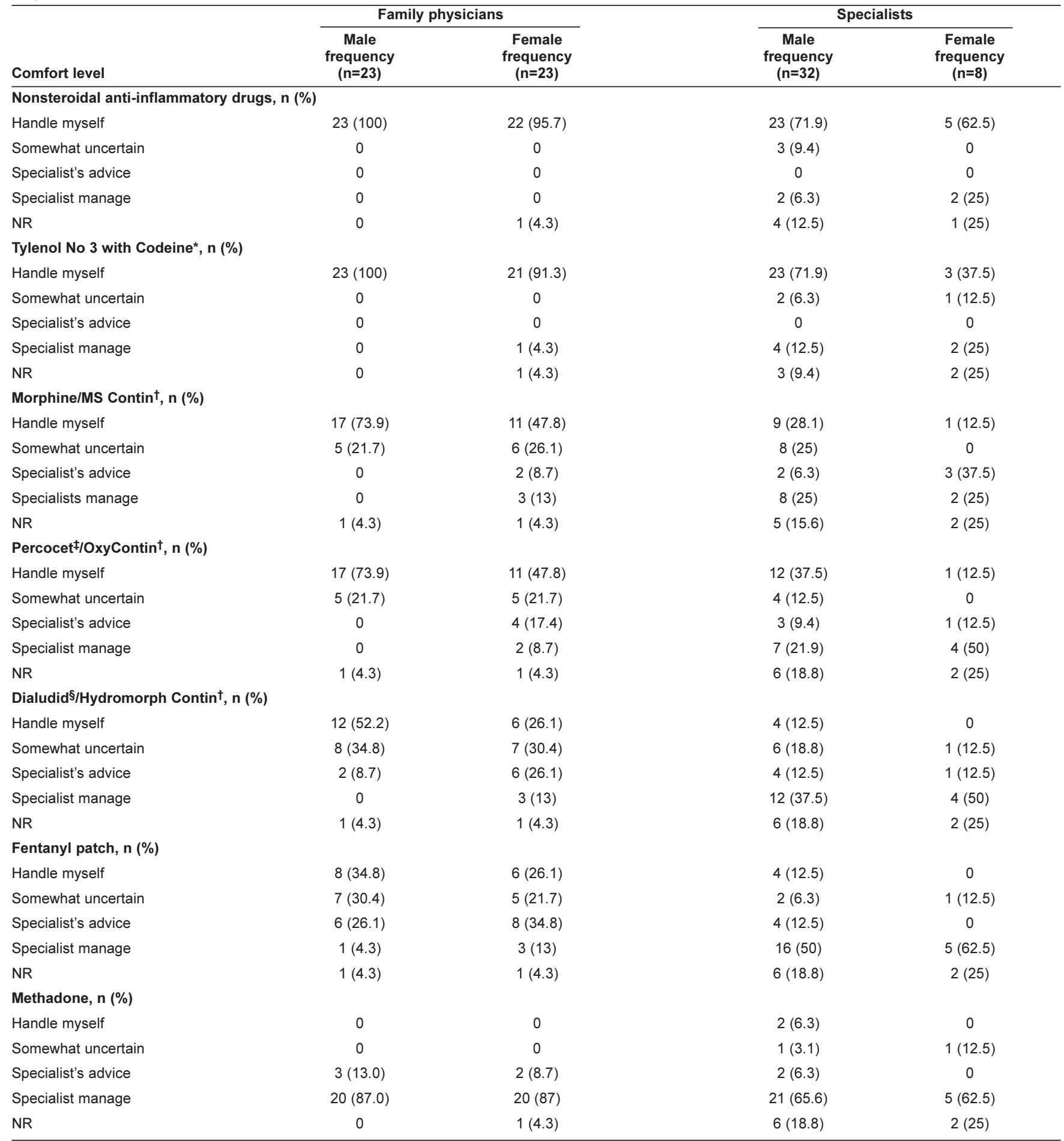

*Janssen-Ortho/McNeil Consumer Healthcare, Canada; †Purdue Pharma, Canada; ¥Bristol-Myers Squibb, Canada; $\$$ Abbott Laboratories, Canada. NR No response

(number of patients managed and the length [years] of practice in Canada). Among the specialists' subgroup, the Spearman's rho test revealed a positive relation, albeit weak, between the significance of pain in physicians' practice and the comfort with methadone (Spearman's rho=0.035 and $\alpha=0.03$ ). See Table 6 for the significance of chronic pain in physicians' practices.
Analysis of the 31 short surveys (14 FP and 17 specialist nonrespondents) revealed that approximately $57.2 \%$ of FPs reported either extremely or very significant influence of chronic pain in their practice compared with $42.9 \%$ reported by the nonrespondents. The nonrespondent specialists responded similarily to the 45 specialists who responded to the long survey. Striking differences were noted within both 
TABLE 5

Significant Mann-Whitney $U$ results detecting sex differences

\begin{tabular}{|c|c|c|c|}
\hline Drug & Mean rank & Mann-Whitney U & $\alpha$ value \\
\hline \multicolumn{4}{|c|}{ Morphine/MS Contin* } \\
\hline Female $(n=22)$ & 18.93 & 163.5 & 0.031 \\
\hline Male $(n=22)$ & 26.07 & & \\
\hline \multicolumn{4}{|c|}{ Percocet ${ }^{\dagger} / O x y C o n t i n *$} \\
\hline Female $(n=22)$ & 18.82 & 161 & 0.026 \\
\hline Male $(n=22)$ & 26.18 & & \\
\hline \multicolumn{4}{|c|}{ Dialudid $¥ /$ Hydromorph Contin* } \\
\hline Female $(n=22)$ & 18.05 & 144 & 0.015 \\
\hline Male $(n=22)$ & 26.95 & & \\
\hline
\end{tabular}

${ }^{*}$ Purdue Pharma, Canada; ${ }^{\dagger}$ Bristol-Myers Squibb, Canada; ${ }^{\ddagger}$ Abbott Laboratories, Canada

subgroups between nonrespondents and repondents regarding the length of practice (FPs' nonrespondents mode $=28$ years and respondents mode $=11$ years; specialists' nonrespondents mode $=13$ years and respondents mode $=7$ years). The majority of respondents and nonrespondents, both FPs and specialists, graduated in Canada and, particularly, in Alberta. Regarding sex, the FPs from the nonrespondents' group had a male to female ratio of 2:1 (compared with 1:1 for the respondents) and specialists had a ratio of 3:1 (compared with $4: 1$ for the respondents). One should note that surveys were sent to 59 male and 56 female FPs (male to female ratio 1:1); in contrast, surveys were sent to 108 male and 34 female specialists (male to female ratio 3:1). The term 'sent' encompasses invitation (and rejection) by phone calls.

\section{DISCUSSION}

In view of the low response rates and the potential that the College of Physicians and Surgeons of Alberta Medical Directory is incomplete, the following discussion cannot be widely generalized (eg, this does not apply to every single physician practicing in Calgary, Alberta). This discussion is only based on the FPs subgroup data, which was deemed more homogeneous than the specialists subgroup. Because of heterogeneity among the specialists' subgroup (Table 1), data emerging from it are not amenable to sound discussion. Nonetheless, it serves as a comparator or quasi control group for the findings from the FP subgroup.

Within the FP subgroup, the respondents were found to be younger, to have devote more hours in direct care of chronic pain patients and to have experienced a higher significance of $\mathrm{CNCP}$ in their practice compared with nonrespondents. This by itself has the potential to threaten generalizability. The following, however, serves as a forum for discussion among health care professionals and policy makers.

A percentage of FPs need a pain specialist's input (advice or talking over management) in managing opioids. This percentage was approximately $12 \%$ for morphine/MS Contin and Percocet/OxyContin, $26.5 \%$ for Dilaudid/Hydromorph Contin, $38.8 \%$ for fentanyl patch and $98 \%$ for methadone. In comparison, no FPs reported the need for pain specialist involvement when managing NSAIDs and, with the exception of a single respondent, the same was true for Tylenol No 3 with Codeine. Evidently, there is a conspicious ommission in physician training. Except for methadone, reasons for these current statistics are not clear. (In Alberta, the use of methadone is restricted and regulated.) In a 2003 Canadian
TABLE 6

Significance of chronic pain in physicians' practices

\begin{tabular}{lcc}
\hline Response & $\begin{array}{c}\text { Family physicians } \\
(\mathbf{n}=\mathbf{4 9})\end{array}$ & $\begin{array}{c}\text { Specialists } \\
(\mathbf{n}=\mathbf{4 5})\end{array}$ \\
\hline Extremely significant, $\mathrm{n}(\%)$ & $14(28.6)$ & $3(6.7)$ \\
Very significant, $\mathrm{n}(\%)$ & $14(28.6)$ & $4(8.9)$ \\
Moderately significant, $\mathrm{n}(\%)$ & $15(30.6)$ & $17(37.8)$ \\
Mildly significant, $\mathrm{n}(\%)$ & $4(8.2)$ & $16(35.6)$ \\
Non-at-all significant, $\mathrm{n}(\%)$ & $1(2.0)$ & $3(6.7)$ \\
Don't know, $\mathrm{n}(\%)$ & 0 & $1(2.2)$ \\
No response, $\mathrm{n}(\%)$ & $1(2.0)$ & $1(2.2)$ \\
\hline
\end{tabular}

survey (7), 29\% of physicians preferred NSAIDs and $16 \%$ preferred acetaminophen as first-line treatment for moderate to severe chronic pain, despite the negative impacts.

Unlike the 2003 study (7), the present survey did not attempt to define the reasons for the FP level of comfort with the various medications. However, in the case of methadone, it is easy to surmise that the requirement for a special license to prescribe this drug greatly discourages FPs from using this medication. In addition, there is a lack of colleagues/teachers capable of helping others increase their comfort level with this drug.

Previous studies $(3,7)$ have identified the following barriers to prescribing opioids:

- potential for addiction;

- potential for patient misuse/abuse;

- fear of side effects;

- fear of audit by regulatory body; and

- cost.

It is interesting that many of these issues are perhaps as applicable to the management of Tylenol No 3 with Codeine as with the other drugs, but the overwhelming majority of respondents in the present study were quite comfortable handing Tylenol No 3 with Codeine themselves. Similarly, 98\% of FPs were comfortable handling NSAIDs, even though this class is associated with greater morbidity (eg, gastrointestinal side effects) than opioids. Indeed, the Alberta College's guidelines for treatment of CNCP support the use of opioids (11). In Alberta, a triplicate prescription program for opioids (not for Tylenol No 3 with Codeine and NSAIDs) signifies college scrutiny and time commitment. This might also decrease the FPs' comfort level with opioids. To add to this, the FPs' fee structure is not perceived to be conducive to the time and efforts spent.

The present study suggests that male FPs in the CHR feel more comfortable handling at least three (of seven) of the drugs in question: morphine/MS Contin, Percocet/OxyContin and Dialudid/Hydromorph Contin. These findings are preliminary and do not allow a definitive conclusion that male FPs perceive less of a risk in prescribing opioids than their female counterparts. However, this hypothesis should be tested much more rigorously.

FPs' low comfort level with opioids may be due to a lack of knowledge. Previous surveys have suggested that FPs want more continuing medical education (eg, the purpose for the Triplicate Prescription Program) in chronic pain management $(2,7)$. If it is not obtained during training (medical school and residency), this knowledge may be difficult to obtain later. 
There are very few chronic pain specialists to provide hands-on and problem-based education. However, unless FPs learn to increase their comfort level with opioids, these same specialists, whose services are already in great demand, can expect to be continually overburdened by referrals for cases of opioid management that might be managed independently by more knowledgeable FPs.

An estimated 8.7 million people suffer from CNCP. Therefore, FPs throughout Canada will be expected to bear the responsibility of caring for them. A lack of sufficiently trained physicians could result in an unmanageable situation.

FUNDING: Physician Partnership Steering Committee, Calgary Health Region and Department of Anesthesiology, University of Calgary, Calgary, Alberta.

\section{REFERENCES}

1. Gardner-Nix J. Opioids and chronic pain. CMAJ 2003;169:904.

2. Moulin DE, Clark AJ, Speechley M, Morley-Forster PK. Chronic pain in Canada - Prevalence, treatment, impact and the role of opioid analgesia. Pain Res Manage 2002;7:179-84.

3. Gardner-Nix J. Principles of opioid use in chronic noncancer pain. CMAJ 2003;169:38-43.

4. Bennett DS, Carr DB. Opiophobia as a barrier to the treatment of pain. J Pain Palliat Care Pharmacother 2002;16:105-9.
5. Savage SR, Joranson DE, Covington EC, Schnoll SH, Heit HA, Gilson AM. Definitions related to the medical use of opioids: Evolution towards universal agreement. J Pain Symptom Manage 2003;26:655-67.

6. Kalso E, Allan L, Dellemijn PL, et al. Recommendations for using opioids in chronic non-cancer pain. Eur J Pain 2003;7:381-6.

7. Simpson KH. Opioids for persistent non-cancer pain: Recommendations for clinical practice. Br J Anaesth 2004;92:326-8.

8. Morley-Forster PK, Clark AJ, Speechley DE, Moulin DE. Attitudes toward opioid use for chronic pain: A Canadian physician survey. Pain Res Manage 2003;8:189-94.

9. Busse JW. Opioids and chronic pain. CMAJ 2003;169:902. (Lett)

10. Russell AS, Aaron SL. Opioids and chronic pain. CMAJ 2003;169:902. (Lett)

11. Turk DC, Brody MC, Okifuji EA. Physicians' attitudes and practices regarding the long-term prescribing of opioids for non-cancer pain. Pain 1994;59:201-8.

12. College of Physicians and Surgeons of Alberta. Management of chronic non-malignant pain. CPSA Guideline 1993. Edmonton: College of Physicians and Surgeons of Alberta, 1993. <www.cpsa.ab.ca/ publicationsresources/attachments_policies/Management $\% 20$ of $\% 20 \mathrm{Chron}$ ic\%20Non-Malignant.pdf> (Version current at October 15, 2004).

13. Weinstein SM, Laux LF, Thornby JI, et al. Physicians' attitudes toward pain and the use of opioid analgesics: Results of a survey from the Texas Cancer Pain Initiative. South Med J 2000;93:479-87.

14. Goldman B. Chronic-pain patients must cope with chronic lack of physician understanding. CMAJ 1991;145:620.

15. College of Physicians and Surgeons of Alberta. Medical Directory. Edmonton: College of Physicians and Surgeons of Alberta, 2002.

16. Henry GT. Practical sampling. Newbury Park: Sage Publication, 1990. 


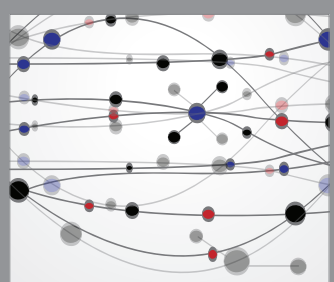

The Scientific World Journal
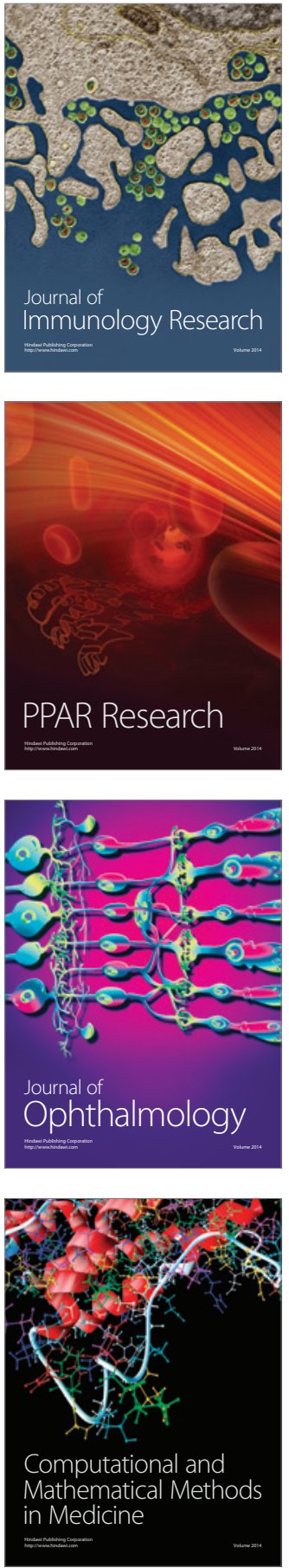

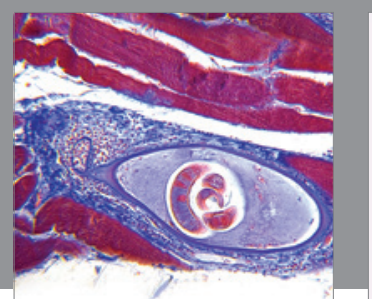

Gastroenterology Research and Practice

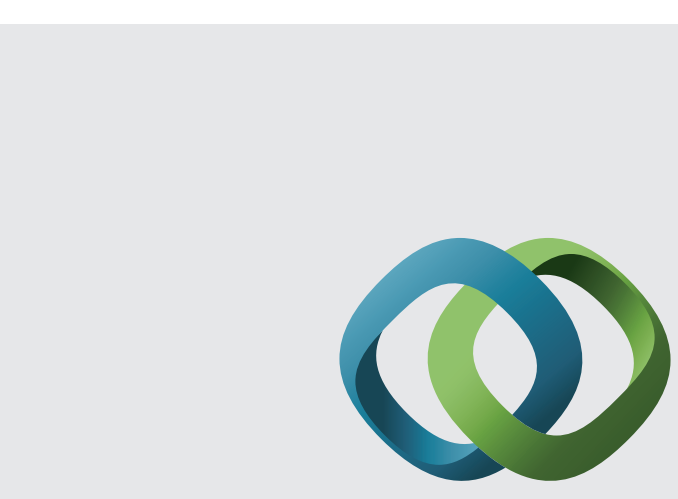

\section{Hindawi}

Submit your manuscripts at

http://www.hindawi.com
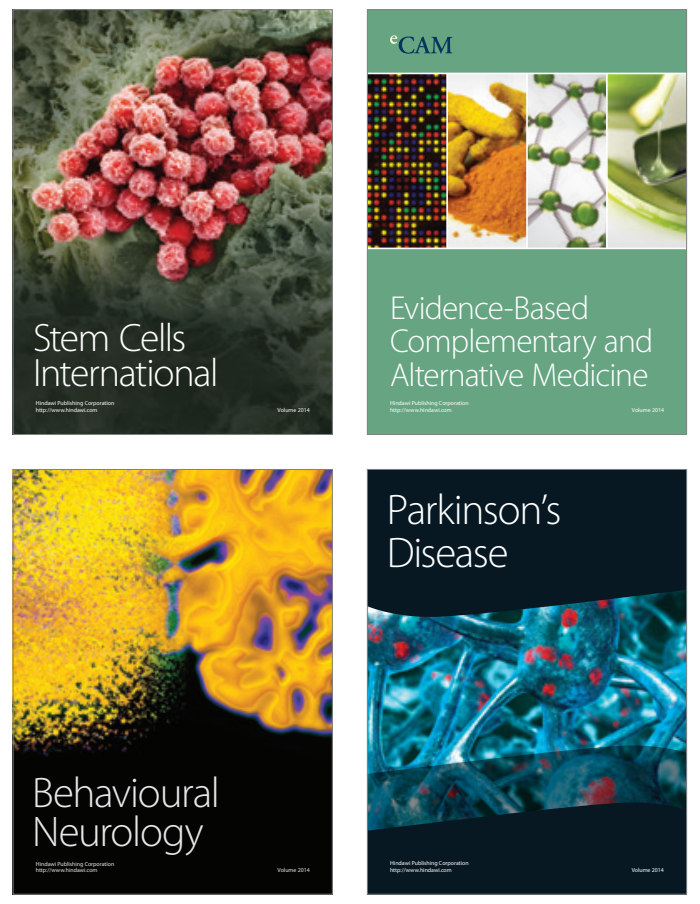
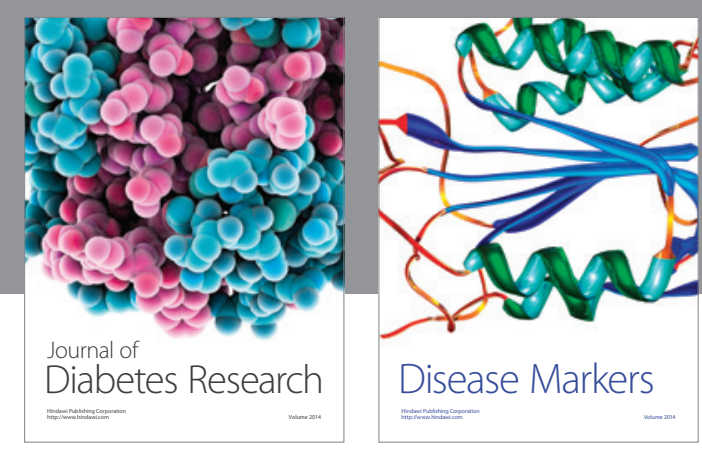

Disease Markers
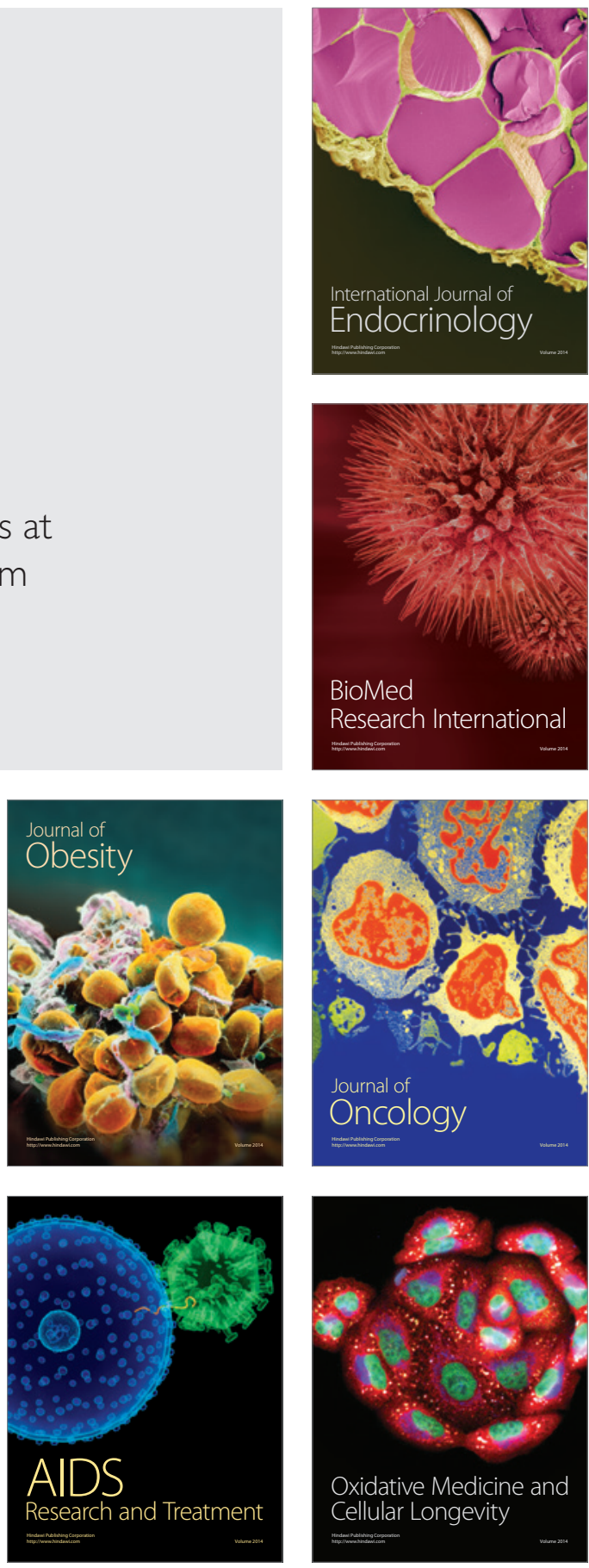